University of Nebraska - Lincoln

DigitalCommons@University of Nebraska - Lincoln

\title{
Boll Weevil (Coleoptera: Curculionidae) Survival through Cotton Gin Trash Fans
}

Thomas W. Sappington

USDA-ARS, tsapping@iastate.edu

Alan D. Brashears

USDA-ARS

Megha N. Parajulee

Texas Agricultural Experiment Station

Stanley C. Carroll

Texas Agricultural Experiment Station

Mark D. Arnold

Texas Agricultural Experiment Station

See next page for additional authors

Follow this and additional works at: https://digitalcommons.unl.edu/usdaarsfacpub

Part of the Agricultural Science Commons

Sappington, Thomas W.; Brashears, Alan D.; Parajulee, Megha N.; Carroll, Stanley C.; Arnold, Mark D.; and Baker, Roy V., "Boll Weevil (Coleoptera: Curculionidae) Survival through Cotton Gin Trash Fans" (2004). Publications from USDA-ARS / UNL Faculty. 727.

https://digitalcommons.unl.edu/usdaarsfacpub/727

This Article is brought to you for free and open access by the U.S. Department of Agriculture: Agricultural Research Service, Lincoln, Nebraska at DigitalCommons@University of Nebraska - Lincoln. It has been accepted for inclusion in Publications from USDA-ARS / UNL Faculty by an authorized administrator of DigitalCommons@University of Nebraska - Lincoln. 
Authors

Thomas W. Sappington, Alan D. Brashears, Megha N. Parajulee, Stanley C. Carroll, Mark D. Arnold, and Roy V. Baker 


\title{
Boll Weevil (Coleoptera: Curculionidae) Survival through Cotton Gin Trash Fans
}

\author{
THOMAS W. SAPPINGTON,${ }^{1}$ ALAN D. BRASHEARS, ${ }^{2}$ MEGHA N. PARAJULEE, ${ }^{3}$ \\ STANLEY C. CARROLL,${ }^{3}$ MARK D. ARNOLD,${ }^{3}$ AND ROY V. BAKER ${ }^{2}$
}

USDA-ARS, Kika de la Garza Agricultural Research Center, 2314 E. Highway 83, Weslaco, TX 78596

J. Econ. Entomol. 97(5): 1612-1618 (2004)

\begin{abstract}
There is concern that cotton gins may serve as loci for reintroduction of boll weevils, Anthonomus grandis grandis Boheman, to eradicated or suppressed zones when processing weevilinfested cotton from neighboring zones. Previous work has shown that virtually all weevils entering the gin in the seed cotton will be removed before they reach the gin stand. Those not killed by the seed cotton cleaning machinery will be shunted alive into the trash fraction, which passes through a centrifugal trash fan before exiting the gin. The objective of this study was to determine survival potential of boll weevils passed through a trash fan. Marked adult weevils were distributed in gin trash and fed through a 82.6-cm (32.5-in.) diameter centrifugal fan operated across a range of fan-tip speeds. A small number of boll weevils were recovered alive immediately after passage through the fan, but all were severely injured and did not survive $24 \mathrm{~h}$. In another experiment, green bolls infested with both adult- and larval-stage weevils were fed through the fan. Several teneral adults survived $24 \mathrm{~h}$, and there was no evidence that fan-tip speed affected either initial survival of weevils, or the number of unbroken boll locks that could harbor an infesting weevil. Thus, designating a minimum fan-tip speed for ensuring complete kill is not possible for the boll weevil. Experiments suggest that a device installed in a gin that partially crushes or cracks bolls open before entering a trash fan will increase mortality, possibly enough that further precautions would be unnecessary.
\end{abstract}

KEY WORDS Anthonomus grandis, boll weevil, cotton gin, trash fans, eradication

The BOLL WEEvIL, Anthonomus grandis grandis Boheman, began an explosive range expansion out of southern Mexico in the 19th century after a host shift to cultivated cotton, entering the United States through the southern tip of Texas in 1892 (Hunter and Coad 1923, Burke et al. 1986). By 1903, it was infesting fields in western Louisiana, and Hunter (1904) concluded that the most important factor in the rapid spread of the boll weevil in the United States was the ginning of infested cotton in uninfested areas. He conducted experiments to identify the points of weevil escape in the cotton gin and recommended modifications in ginning practices to help slow the spread of the destructive pest (Hunter 1904). One hundred years later, the cotton industry is faced with the same problem, but for a different reason. The boll weevil's range is being steadily diminished in the U.S. by extensive

Mention of trade names or commercial products in this article is solely for the purpose of providing specific information and does not imply recommendation or endorsement by the U.S. Department of Agriculture.

${ }^{1}$ Corresponding author. Current address: USDA-ARS-CICGRU, Genetics Laboratory, Iowa State University, Ames, IA 50011 (e-mail: tsapping@iastate.edu).

${ }^{2}$ USDA-ARS-CPPRU, Lubbock, TX 79401.

${ }^{3}$ Texas Agricultural Experiment Station, Lubbock, TX 79403. eradication programs (Smith 1998, Dickerson et al. 2001, Grefenstette and El-Lissy 2003). In some states, such as Texas, neighboring eradication zones often differ substantially in their levels of infestation (Allen et al. 2003). There is concern that gins operating in areas where boll weevil populations have been eradicated or greatly suppressed may act as sites of reinfestation when serving customers who harvest cotton in a nearby area where weevil populations are still high.

Sappington et al. (2004a) demonstrated that adult boll weevils are commonly packed alive into modules, which are large free-standing stacks of cotton used to store the harvested cotton until the gin is ready to process it (Lalor et al. 1994). In addition, stripperharvested cotton can contain many green bolls (Laird et al. 1994), which are sometimes heavily infested with boll weevil larvae, pupae, and unemerged teneral adults (Sappington et al. 2004a). Even picker-harvested cotton can contain a small number of green bolls (T.W.S., unpublished data). Most, perhaps all, weevils entering the gin either as free adults or as immatures in various stages of development inside infested bolls will be removed or killed by seed cotton cleaning machinery before reaching the gin stand (Sappington et al. 2004b). Although many weevils are 
killed by the machinery, it is expected that some weevils will be segregated alive into the trash fraction, as will green bolls infested with live insects. Foreign material removed from the seed cotton is pulled through a trash fan (Baker et al. 1994) where it is pulverized before entering a cyclone. The cyclone separates the conveying air from the trash and dust that drop into a bur hopper for temporary storage until loaded into a truck (Parnell et al. 1994). Trash fans are an important source of mortality for another major pest of cotton, the pink bollworm, Pectinophora gossypiella (Saunders). To prevent spread and reinfestations of this quarantined insect from gin plants, trash fans must be operated at a minimal speed shown experimentally to destroy bollworm larvae in trash and green bolls (Robertson et al. 1959, 1963; Hughs and Gillum 1994; Hughs and Staten 1995). Our objectives in the current study were to characterize mortality of both free adults and various life stages in infested bolls when passed through a centrifugal fan operated over a range of fan-tip speeds. We hoped to determine a minimum speed at which all weevils will be killed, which could be adopted as a standard for the gins operating in areas at-risk for boll weevil reintroductions.

\section{Materials and Methods}

All experiments were conducted in the research gin at the USDA-ARS Cropping Systems Research Laboratory in Lubbock, TX.

Survival of Free Adults. Adult boll weevils were obtained from the laboratory colony maintained at the USDA-APHIS Mission Plant Protection Center in Mission, TX. The weevils were of variable age but usually between 1 and 3 wk old.

Several fan-tip speeds were tested for their effects on mortality of free adult boll weevils. In an initial experiment, lots of 100 weevils were marked with fluorescent powder (Switzer Brothers, Cleveland, $\mathrm{OH}$ ) and uniformly distributed in $3.6 \mathrm{~kg}(8 \mathrm{lb})$ of gin trash spread evenly along a 1.8-m (6-foot)-long by 0.33-m (13.25-in.) wide conveyor belt. The weevilseeded trash was fed into a 40-cm (16-in.)-diameter 2.44-m (8-foot)-long pipe leading to a centrifugal fan with a 82.6-cm (32.5-in.)-diameter flat blade impeller operating at one of seven fan-tip speeds: 56.2, 60.5, $64.8,69.2,73.5,77.8$, and $82.1 \mathrm{~m} / \mathrm{s}(184,199,213,227$, 241,255 , and $269 \mathrm{feet} / \mathrm{s}$, respectively; 1,300, 1,400, $1,500,1,600,1,700,1,800$, and 1,900 rpm, respectively). Each fan-tip speed was tested three times, except the $56.2,69.2$, and $82.1 \mathrm{~m} / \mathrm{s}$ treatments, which were tested six times. Static air velocity inside the pipe was maintained at $2.54 \mathrm{~cm}$ ( $1 \mathrm{in}$.) of water, as measured with a liquid manometer (Baker et al. 1994), for all fan speeds. In a second experiment, lots of 300 marked weevils were distributed in $9.1 \mathrm{~kg}(20 \mathrm{lb})$ of gin trash and were introduced to the fan in the same manner, and tested at fan-tip speeds of 56.2, 60.5, 64.8, 69.2, and $73.5 \mathrm{~m} / \mathrm{s}$. Each speed treatment was replicated four times, except the $56.2 \mathrm{~m} / \mathrm{s}$ treatment, which was replicated five times.
In both experiments, all debris was collected and sorted by hand under blacklight lamps, which facilitated recovery of fluorescently marked weevils and weevil parts. The number of live weevils was recorded. In the second experiment, the number of dead weevils retaining at least half the body intact also was recorded. Live weevils were placed in a covered petri dish with a water-soaked piece of cotton and were checked again after $24 \mathrm{~h}$ for continued survival.

Survival of Weevils Inside Unopened Green Bolls. Large numbers of unopened green bolls were collected near Lubbock, TX. Most were $2.5-3 \mathrm{~cm}$ in diameter and were typical of green bolls that are harvested from fields not pretreated with a desiccant. Those with sealed punctures, indicating that they were potentially infested (Everett and Earle 1964, Greenberg et al. 2004), were segregated and used in the experiments. Lots of 50 bolls were fed by conveyor belt at $\approx 2.5$ bolls per second into galvanized pipe leading to the fan as described above for free weevils, except the bolls were not embedded in gin trash. There were two fan inlet treatments evaluated, straight and elbowed. We reasoned that striking an elbow at high speed might partially open some of the bolls, possibly increasing the damage they would suffer when passing through the fan. In the first treatment, bolls were carried in an airstream through 340 $\mathrm{cm}$ ( $134 \mathrm{in}$.) of pipe to a $90^{\circ}$ elbow, followed by a $53-\mathrm{cm}$ (21-in.) transition section connecting the 40-cm (16in.)-diameter elbow to the 47.6-cm (18.75-in.)-diameter fan inlet. All seven fan-tip speeds were tested three times each in the experiment with elbowed pipe. In the second treatment, bolls passed directly down $183 \mathrm{~cm} \mathrm{(72} \mathrm{in.)} \mathrm{of} \mathrm{straight} \mathrm{pipe} \mathrm{to} \mathrm{the} \mathrm{fan.} \mathrm{Three}$ speeds, 56.2, 69.2, and $82.1 \mathrm{~m} / \mathrm{s}$, were tested three times each in the experiment containing straight pipe. All debris was collected and sorted by hand under normal lighting, and the number of live larvae, pupae, and adults was recorded. Any live weevils were placed in a covered petri dish with a water-soaked piece of cotton and were checked again after $24 \mathrm{~h}$ for continued survival. In addition, the numbers of unbroken locks of forming cotton fiber inside bolls that could potentially provide a safe haven for a weevil were recorded. There are usually four locks per boll, but three or five locks are occasionally observed.

Replications of various fan-tip speed and pipe treatments were conducted on 14,20,21, 25, 27, and 28 September 2001. Bolls for the experiments were collected on 14, 19, 21, and 26 September. For the elbowed-pipe experiment, aliquots of 50 bolls were dissected on the day that each experiment was conducted to determine expected numbers of each life stage of infesting weevils (Table 1 ). In the straight-pipe experiment, infested bolls were kept refrigerated to slow insect development and used within $2 \mathrm{~d}$ of collection, so only one aliquot of 50 bolls was dissected. Because the weevils were continuously developing in the field, and continued to develop in the laboratory after boll collection (except when refrigerated), the life stage distribution in the experimental bolls varied with date (Table 1). 
Table 1. Distribution of boll weevil life stages infesting a subsample of bolls before passage through a gin trash fan operated at indicated fan-tip speeds (meters per second) on given dates

\begin{tabular}{|c|c|c|c|c|c|c|c|c|}
\hline \multirow{2}{*}{$\begin{array}{c}\text { Boll } \\
\text { treatment }\end{array}$} & \multirow{2}{*}{$\begin{array}{c}\text { Pipe } \\
\text { treatment }\end{array}$} & \multirow{2}{*}{$\begin{array}{l}\text { Test date } \\
(\mathrm{m} / \mathrm{d} / \mathrm{yr})\end{array}$} & \multirow{2}{*}{$\begin{array}{l}\text { No. bolls } \\
\text { dissected }\end{array}$} & \multicolumn{3}{|c|}{ Stage distribution (no./50 bolls) } & \multirow{2}{*}{$\begin{array}{c}\text { Fan-tip } \\
\text { speed }\end{array}$} & \multirow{2}{*}{$\begin{array}{l}\text { No. } \\
\text { replicates } \\
\text { tested }\end{array}$} \\
\hline & & & & Larvae & Pupae & Adults & & \\
\hline \multirow[t]{13}{*}{ Unopened } & \multirow[t]{10}{*}{ Elbow } & \multirow[t]{3}{*}{$9 / 14 / 2001$} & \multirow[t]{3}{*}{50} & \multirow[t]{3}{*}{20} & \multirow[t]{3}{*}{5} & \multirow[t]{3}{*}{0} & 56.2 & 1 \\
\hline & & & & & & & 60.5 & 1 \\
\hline & & & & & & & 64.8 & 1 \\
\hline & & \multirow[t]{4}{*}{$9 / 20 / 2001$} & \multirow[t]{4}{*}{50} & \multirow[t]{4}{*}{3} & \multirow[t]{4}{*}{17} & \multirow[t]{4}{*}{5} & 56.2 & 2 \\
\hline & & & & & & & 60.5 & 2 \\
\hline & & & & & & & 64.8 & 2 \\
\hline & & & & & & & 69.2 & 3 \\
\hline & & $9 / 21 / 2001$ & 50 & 8 & 16 & 14 & 73.5 & 3 \\
\hline & & \multirow[t]{2}{*}{$9 / 25 / 2001$} & \multirow[t]{2}{*}{50} & \multirow[t]{2}{*}{0} & \multirow[t]{2}{*}{2} & \multirow[t]{2}{*}{13} & 77.8 & 3 \\
\hline & & & & & & & 82.1 & 3 \\
\hline & \multirow[t]{3}{*}{ Straight } & \multirow[t]{3}{*}{$9 / 27-28 / 2001$} & \multirow[t]{3}{*}{50} & \multirow[t]{3}{*}{1} & \multirow[t]{3}{*}{6} & \multirow[t]{3}{*}{15} & 56.2 & 3 \\
\hline & & & & & & & 69.2 & 3 \\
\hline & & & & & & & 82.1 & 3 \\
\hline \multirow[t]{13}{*}{ Cracked } & Elbow & $8 / 19 / 2002$ & 25 & 5 & 8 & 12 & 56.2 & 2 \\
\hline & & & & & & & 69.2 & 3 \\
\hline & & $8 / 20 / 2002$ & 25 & 13 & 5 & 6 & 56.2 & 1 \\
\hline & & & & & & & 60.5 & 5 \\
\hline & & $8 / 21 / 2002$ & 25 & 13 & 10 & 3 & 56.2 & 2 \\
\hline & & & & & & & 64.8 & 5 \\
\hline & & & & & & & 69.2 & 2 \\
\hline & & & & & & & 73.5 & 2 \\
\hline & & $8 / 22 / 2002$ & 25 & 18 & 8 & 4 & 73.5 & 3 \\
\hline & Straight & & & & & & 64.8 & 5 \\
\hline & & & & & & & 69.2 & 5 \\
\hline & & $8 / 23 / 2002$ & 25 & 13 & 5 & 6 & 73.5 & 5 \\
\hline & & & & & & & 77.8 & 4 \\
\hline
\end{tabular}

Survival of Weevils Inside Slightly Cracked Green Bolls. A follow-up experiment was conducted to determine whether slightly cracking weevil-infested bolls before passage through a trash fan increases mortality of the infesting weevils over that observed in uncracked bolls. A large number of bolls were collected on 16 August 2002 in the Lower Rio Grande Valley of Texas near Weslaco, and those potentially infested were segregated as described above. Immediately before each run, the distal end of each test boll was slightly cracked along the sutures delimiting the boll's locks by pressing with thumb and forefinger or with pliers. Lots of 50 cracked, infested bolls were fed into elbowed or straight pipe as described above. In the elbowed pipe experiment, the fan was tested at tip speeds of $56.2,60.5,64.8,69.2$, and $73.5 \mathrm{~m} / \mathrm{s}$, with five replications per speed. In the straight pipe experiment, the fan was tested at tip speeds of $64.8,69.2,73.5$, and $77.8 \mathrm{~m} / \mathrm{s}$. There were five replications per speed treatment except the $82.1 \mathrm{~m} / \mathrm{s}$ treatment, which was replicated only four times because there were not enough bolls to conduct a fifth replication. Debris was collected and processed as described previously. Lots of 25 bolls were dissected each day of the experiment (19-23 August 2002) to determine expected numbers of each life stage (Table 1).

Statistical Analyses. Initial survival of weevils of a given stage infesting bolls is expressed and analyzed as the percentage of that expected based on the distribution of life stages observed in the dissected subsamples for a given date. The effect of fan-tip speed, pipe shape (elbowed or straight), and boll treatment (unopened or cracked) on percentage of initial sur- vival, percentage of dead weevils recovered, and number of undamaged boll locks was tested with the nonparametric Kruskal-Wallis one-way analysis of variance (ANOVA) by ranks by using Statistix software (Analytical Software 2000). This procedure generates a Kruskal-Wallis test statistic $(H)$ that is used to test the null hypothesis that the distributions of mean ranks for all groups are similar, but it is generally conceptualized as a test for differences in medians (Kruskal and Wallis 1952, van der Laan and Verdooren 1987, Daniel 1990, Analytical Software 2000). $H$ approximately follows a $\chi^{2}$ distribution with $k-1$ degrees of freedom, where $k$ is the number of groups sampled (Kruskal 1952), so the probability values $(P)$ reported here are based on the $\chi^{2}$ approximation (Daniel 1990, Analytical Software 2000). Follow-up multiple pairwise comparisons of treatments were performed (Analytical Software 2000) using the comparison of mean ranks procedure corrected for experimentwise error rate (Dunn 1964), as described in detail by Daniel (1990).

\section{Results and Discussion}

Survival of Free Adults. In the first experiment, no live free adult boll weevils were recovered from the gin trash after passage through fans operated at any tested fan-tip speed. In the second experiment, where the number of adults tested per replication was increased from 100 to 300 , a few weevils were found alive after passage through fans operating at tip-speeds of 60.5 through $69.2 \mathrm{~m} / \mathrm{s}$, but all were badly mutilated, and none survived to $24 \mathrm{~h}$ (Fig. 1). Fan speed had no 


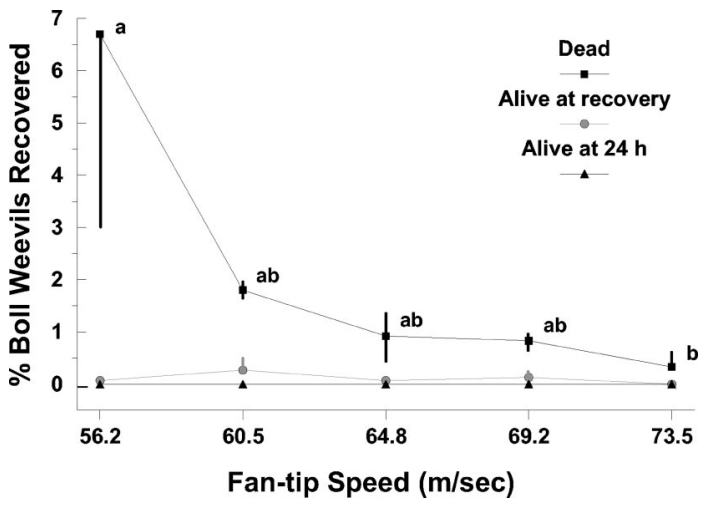

Fig. 1. Mean percentage of recovery of 300 marked boll weevil adults within gin trash after passage through a centrifugal fan operated at indicated fan-tip speeds. Dead weevils were counted if at least half the body was found intact. All live weevils recovered were badly damaged and were held for $24 \mathrm{~h}$ to check for long-term viability; none survived. Vertical bar indicates SE. Means followed by the same letter indicate that medians from those treatment groups are not significantly different (comparison of mean ranks procedure, $\alpha=0.05$; Dunn 1964).

significant effect on initial percentage of recovery of live adults $(H=1.67, \mathrm{df}=4, P=0.80)$. In both experiments, weevil body parts were common in the trash, indicating that the low recovery of even dead weevils was due to near total destruction of the weevils' bodies by the fan. The number of dead weevils recovered from the trash that retained at least half of a body declined significantly with increasing fan-tip speed $(H=11.18, \mathrm{df}=4, P=0.02)$ (Fig. 1$)$, which suggests a corresponding decrease in the likelihood of weevil survival as fan speed increases.

Hunter (1904) passed several hundred marked adult boll weevils through a 112-cm (44-in.)-diameter centrifugal fan operating at a fan-tip speed of 105.4 $\mathrm{m} / \mathrm{s}$, and found no survivors, but lower speeds were not tested. Robertson et al. (1959) found no survival of pink bollworm larvae mixed in with gin trash at fan-tip speeds above $62.5 \mathrm{~m} / \mathrm{s}$. Although adult boll weevils are hard bodied compared with pink bollworm larvae, we found no evidence that they could survive the lowest fan-tip speed tested $(56.2 \mathrm{~m} / \mathrm{s})$. The $95 \%$ upper confidence level $\left(p_{u}\right)$ calculated for the observed zero rate of survival to $24 \mathrm{~h}$ of the total of 2,100 boll weevils tested at the $56.2 \mathrm{~m} / \mathrm{s}$ fan-tip speed is 0.00143 , or $0.143 \%$. This represents the statistical worst case for potential boll weevil survival based on sample size alone at the lowest fan speed tested (Couey and Chew 1986, Venette et al. 2002, Sappington et al. $2004 b$ ). Because increasing fan-tip speed treatments provided progressively harsher conditions, the sample sizes for the lower speeds tested can be pooled for calculating the $95 \%$ upper confidence levels of the greater fan speeds. Thus, in the statistically worst case based solely on sample size, $0.083,0.059,0.043,0.036$, 0.030 , and $0.026 \%$ of free adult weevils could be expected to survive fan-tip speeds of $60.5,64.8,69.2,73.5$, 77.8 , and $82.1 \mathrm{~m} / \mathrm{s}$, respectively. True survival poten- tial at any of the fan-tip speeds tested is undoubtedly much closer to zero than to the calculated $95 \%$ upper confidence levels because only a few cadavers and briefly surviving weevils were recovered (Fig. 1), all badly mutilated.

Survival of Weevils Inside Unopened Green Bolls. Bolls are expected to provide infesting insects some protection against the impact of the fan blade (Hughs and Staten 1995), and we found this to be the case for boll weevil. Our experiment was complicated by the necessary spread of boll collection and use over a 2-wk period, resulting in some variation in relative distribution of life stages by collection date and test date (Table 1). For example, larvae were more prevalent early in the experiment, whereas teneral adults were more prevalent later. Nevertheless, our results indicated that although mortality was high for all life stages at all fan-tip speeds tested, there was some initial survival of boll-encased teneral adults even at the highest speed tested $(82.1 \mathrm{~m} / \mathrm{s})$ (Table 2). Most of these adults were severely damaged and only a few survived to $24 \mathrm{~h}$. However, one adult weevil survived to at least $24 \mathrm{~h}$ after passing through a fan operated at $73.5 \mathrm{~m} / \mathrm{s}$. Percentage of initial survival was not significantly affected by fan-tip speed in either the elbowed pipe experiment $(H=4.46, \mathrm{df}=6, P=0.62)$ or the straight pipe experiment $(H=5.05 ; \mathrm{df}=2 ; P=0.05)$, in which only three fan-tip speeds were tested (Table 2 ). Whether the pipe leading to the fan was elbowed or straight had no significant affect on percentage of initial survival $(H=0.013, \mathrm{df}=2, P=0.91)$.

No live boll weevil pupae were recovered. Two live larvae were recovered, one each at fan-tip speeds of 56.2 and $60.5 \mathrm{~m} / \mathrm{s}$, but they were damaged and did not survive to $24 \mathrm{~h}$ (Table 2). Hughs and Staten (1995) found a low rate of survival of pink bollworm larvae infesting green bolls when passed through a fan operated at a tip speed of $65.5 \mathrm{~m} / \mathrm{s}$, but no survival at speeds equal to or higher than $68.8 \mathrm{~m} / \mathrm{s}$. In their study, survival of pink bollworm was scored by the number of moths eventually emerging from the boll trash, so initial survival was not determined.

Although the bolls were always opened and severely damaged by the fan, occasional locks of cotton inside bolls survived intact (Table 3). If such a lock were inhabited by a boll weevil, the latter could presumably survive, then emerge and escape. Thus, the number of unbroken locks after passage through a fan can serve as a worst-case index of potential weevil survival. Substantial numbers of unbroken locks were observed only in the experiment testing uncracked bolls and an elbowed pipe (Table 3). In this experiment, the number of surviving intact locks was not significantly affected by fan-tip speed $(H=9.21, \mathrm{df}=$ $6, P=0.16)$. The number of unbroken locks from unopened bolls was significantly greater when using the elbowed pipe arrangement $(1.3+0.29)$ than when using the straight pipe arrangement $(0.0+0.00)(H=$ 8.64 , $\mathrm{df}=1, P=0.002$ ), suggesting that the elbow did not help break up the bolls. Why significantly more locks survived the elbow treatment than the straight pipe treatment is unclear. 
Table 2. Mean \pm SE (\%) initial recovery of live boll weevils (and mean percentage still alive at $24 \mathrm{~h}$ ) in debris after passage of 50 infested green bolls through a gin trash fan operated at indicated fan-tip speeds

\begin{tabular}{|c|c|c|c|c|c|c|c|}
\hline \multirow{2}{*}{ Pipe } & \multirow{2}{*}{$\begin{array}{c}\text { Fan-tip } \\
\text { speed }(\mathrm{m} / \mathrm{s})\end{array}$} & \multicolumn{3}{|c|}{ Recovered alive from unopened bolls ${ }^{a}$} & \multicolumn{3}{|c|}{ Recovered alive from cracked bolls ${ }^{a}$} \\
\hline & & Larvae $^{b}$ & Pupae & Adults $^{b}$ & Larvae & Pupae & Adults $^{b}$ \\
\hline \multirow[t]{7}{*}{ Elbow } & 56.2 & $1.7 \pm 1.67(0)$ & 0 & $10.0 \pm 10.00(10.0)$ & 0 & 0 & $6.7 \pm 6.67(0)$ \\
\hline & 60.5 & $1.7 \pm 1.67(0)$ & 0 & 0 & 0 & 0 & $20.0 \pm 8.16(0)$ \\
\hline & 64.8 & 0 & 0 & $10.0 \pm 10.00(0)$ & 0 & 0 & $6.7 \pm 6.67(0)$ \\
\hline & 69.2 & 0 & 0 & 0 & 0 & 0 & 0 \\
\hline & 73.5 & 0 & 0 & $7.1 \pm 4.12(2.4)$ & 0 & 0 & 0 \\
\hline & 77.8 & 0 & 0 & $7.7 \pm 4.44(0)$ & nt & nt & nt \\
\hline & 82.1 & 0 & 0 & $5.1 \pm 5.13(0)$ & nt & nt & nt \\
\hline \multirow[t]{6}{*}{ Straight } & 56.2 & 0 & 0 & $6.7 \pm 3.85(0)$ & nt & nt & nt \\
\hline & 64.8 & nt & nt & nt & 0 & 0 & $15.0 \pm 6.12(0)$ \\
\hline & 69.2 & 0 & 0 & $11.1 \pm 2.22(4.4)$ & 0 & 0 & $10.0 \pm 6.12(0)$ \\
\hline & 73.5 & nt & nt & nt & 0 & 0 & $3.3 \pm 3.33(0)$ \\
\hline & 77.8 & nt & nt & nt & 0 & 0 & $8.3 \pm 4.81(0)$ \\
\hline & 82.1 & 0 & 0 & 0 & nt & nt & nt \\
\hline
\end{tabular}

At introduction, bolls were either unopened or slightly cracked at apex of boll along the natural sutures delimiting locks. nt, not tested. Means within a column for each pipe treatment are not significantly different (comparison of mean ranks procedure, $\alpha=0.05$, Dunn 1964).

${ }^{a}$ Expressed as percentage of expected. Expected recovery was calculated from an initial density of $x$ weevils/ 50 bolls, where $x$ is the number of a given infesting stage found per 50 bolls dissected on dates each fan-tip speed was tested (see Table 1).

${ }^{b}$ Number in parentheses indicates percentage of initial expected that survived to $24 \mathrm{~h}$.

Survival of Weevils Inside Slightly Cracked Green Bolls. Because we found evidence for at least limited survival and for unbroken locks at the highest fan-tip speeds tested, we conclude that trash fans alone cannot be relied upon to destroy all weevils inside infested bolls as they are shunted out of the seed cotton during precleaning. If a device could be deployed in the gin to mechanically crack open bolls before they reached a fan, the bolls and any infesting weevils they were harboring might be more susceptible to destruction by the fan. To test this concept, we introduced mechanically cracked bolls to the trash fan. There was no significant effect of fan-tip speed on percentage of initial survival within either the elbowed pipe $(H=$ $7.20, \mathrm{df}=4, P=0.13)$ or straight pipe $(H=2.78, \mathrm{df}=$ $3, P=0.43$ ) experiments using cracked bolls (Table 2 ). Likewise, there was no significant difference in percentage of initial survival between elbowed and straight pipe $(H=0.92, \mathrm{df}=1, P=0.34)$. Even though each boll was only slightly cracked at its apex, there was a dramatic decrease in the number of undamaged locks in cracked bolls compared with unopened bolls $(H=17.57, \mathrm{df}=1, P<0.0001)$ (Table 3). Although there was no significant difference in the percentage of initial recovery of live adults in unopened or cracked bolls $(H=0.05, \mathrm{df}=1, P=0.82$ ) (Table 2$)$, all of those recovered from the latter were severely damaged and none survived to $24 \mathrm{~h}$. Together, our data indicate that preliminary cracking open of bolls will increase mortality of infesting weevils and that design and installation of a device for accomplishing that end would decrease the chances of weevil escape in gin trash.

In conclusion, previous work has shown that modern seed cotton cleaning machinery in the gin is very good at removing boll weevil adults before they reach the gin stand (Sappington et al. 2004b). Any weevils removed with the trash that are not killed directly by the cleaning equipment represent potential dispersants that could reinfest an eradication zone, unless they are killed by a trash fan as they exit the gin. Gins use trash fans of a variety of sizes, and we tested only one size. However, Hughs and Staten (1995) demonstrated that the important parameter in killing insects is fan-tip speed rather than size or rpm, making our results widely applicable. Our data indicate that free adult boll weevils do not survive passage through a centrifugal fan operating at a tip-speed of at least 56.2 $\mathrm{m} / \mathrm{s}$.

Boll weevils surviving a trash fan in infested bolls are another matter. Most green bolls picked up by a harvester are removed early on, sometimes by green boll removers mounted on stripper-type harvesters, and always by a green boll trap incorporated into the gin unloading system (Laird et al. 1994). However, $\approx 10 \%$ of harvested bolls can be expected to enter the seed cotton cleaning machinery (Laird et al. 1994), where they will be removed with other gin trash and passed through a trash fan. A cornerstone of pink bollworm quarantine guidelines is that trash fans must operate at a minimum fan-tip speed that has been shown to kill most, and presumably all, larvae in infested bolls (Rob-

Table 3. Mean ( \pm SE) no. of undamaged (complete) locks of cotton recovered in debris after passage of 50 infested green bolls through a gin trash fan operated at indicated fan-tip speeds

\begin{tabular}{cccccc}
\hline \hline \multirow{2}{*}{$\begin{array}{c}\text { Fan-tip } \\
\text { speed }(\mathrm{m} / \mathrm{s})\end{array}$} & $\begin{array}{c}\text { Straight } \\
\text { pipe }\end{array}$ & $\begin{array}{c}\text { Elbowed } \\
\text { pipe }\end{array}$ & & $\begin{array}{c}\text { Straight } \\
\text { pipe }\end{array}$ & $\begin{array}{c}\text { Elbowed } \\
\text { pipe }\end{array}$ \\
\cline { 6 - 7 } \cline { 5 - 6 } & 0 & $1.7 \pm 0.33$ & & nt & 0 \\
66.2 & nt & 0 & & nt & $0.2 \pm 0.20$ \\
64.8 & nt & $0.3 \pm 0.33$ & & 0 & 0 \\
69.2 & 0 & $1.3 \pm 0.88$ & & 0 & 0 \\
73.5 & nt & $2.0 \pm 0.58$ & & 0 & $0.2 \pm 0.20$ \\
77.8 & nt & $1.3 \pm 1.33$ & & 0 & nt \\
82.1 & 0 & $2.3 \pm 0.88$ & & nt & nt \\
\hline
\end{tabular}

Introduced bolls were either unopened or slightly cracked at apex of boll along the natural sutures delimiting locks. Undamaged locks serve as an index of survival potential of infesting boll weevils nt, not tested. 
ertson et al. 1959, Hughs and Gillum 1994, Hughs and Staten 1995). In contrast, although the kill rate is very high, our study failed to demonstrate a high enough fan-tip speed that can ensure complete kill of boll weevils infesting green bolls. Indeed, fan-tip speeds ranging from 56.2 to $82.1 \mathrm{~m} / \mathrm{s}$ seem to be equivalent in their destructive effect on bolls and infesting adult boll weevils. Although operation at tip speeds of $91.5 \mathrm{~m} / \mathrm{s}$ (Baker et al. 1994) or higher is possible for some fans, we could not test fan tip speeds above $82.1 \mathrm{~m} / \mathrm{s}$ in our study due to safety limitations.

Thus, a recommendation for a simple minimum fantip speed to ensure complete kill, as is now in place for pink bollworm quarantine regulations (Hughs and Gillum 1994), is not possible for boll weevils. An obvious, but rather unpalatable, solution would be for gins in eradication zones to cease ginning cotton harvested by customers in neighboring infested zones. Alternatively, a technological resolution may be possible. Our data suggest that a device that partially crushes or cracks bolls open before entering the first trash disposal fan will increase boll weevil mortality, possibly enough that further precautions would be unnecessary. The material removed from the seed cotton that passes through the first trash fan will include virtually all bolls that escaped removal by the green boll trap. Trash handled by other fans further down the line is of no concern because it will contain only free adult weevils, and we found no evidence that free boll weevils can survive even low fan-tip speeds. Until alternative technology is developed and tested, however, at-risk gins should consider other precautions either for limiting the number of green bolls entering the gin, or for handling that portion of the trash that is removed early in the ginning process.

\section{Acknowledgments}

We thank Latha Bommireddy, Veronica Cardoza, Jimmy Castro, Andy Cranmer, Valentina Greenberg, Lanthia Jones, Anand Sapkota, R. B. Shrestha, Bill Turner, and Orlando Zamora for technical assistance. We also thank Leeda Wood for providing laboratory-reared boll weevils. Funding was provided in part by grants IPM01-023 to R.B. and T.W.S. and by IPM02-004 to T.W.S. and A.D.B. from the Texas Department of Agriculture. Mention of trade names or commercial products in this article is solely for the purpose of providing specific information and does not imply recommendation or endorsement by the U.S. Department of Agriculture.

\section{References Cited}

Allen, C. T., L. E. Smith, L. W. Patton, and R. O. Newman. 2003. Status of boll weevil eradication in Texas, pp. 1340 1345. In Proceedings, Beltwide Cotton Conferences, 6-10 January, Nashville, TN. National Cotton Council, Memphis, TN.

Analytical Software. 2000. Statistix for Windows, version 7.0: user's manual. Analytical Software, Tallahassee, FL.

Baker, R. V., E. P. Columbus, R. C. Eckley, and B. J. Stanley. 1994. Pneumatic and mechanical handling systems, pp. 143-171. In W. S. Anthony and W. D. Mayfield (eds.), Cotton Ginners Handbook. U.S. Department of Agriculture, Agricultural Handbook 503.
Burke, H. R., W. E. Clark, J. R. Cate, and P. A. Fryxell. 1986. Origin and dispersal of the boll weevil. Bull. Entomol. Soc. Am. 32: 228-238.

Couey, H. M., and V. Chew. 1986. Confidence limits and sample size in quarantine research. J. Econ. Entomol. 79: 887-890.

Daniel, W. W. 1990. Applied Nonparametric Statistics. PWS-KENT Publishing Company, Boston, MA.

Dickerson, W. A., A. L. Brashear, J. T. Brumley, F. L. Carter, W. J. Grefenstette, and F. A. Harris. 2001. Boll weevil eradication in the United States through 1999. The Cotton Foundation Publisher, Memphis, TN.

Dunn, O. J. 1964. Multiple comparisons using rank sums. Technometrics 6: 241-252.

Everett, T. R., and N. W. Earle. 1964. Boll weevil oviposition responses in cotton squares and various other substrates. J. Econ. Entomol. 57: 651-656.

Greenberg, S. M., T. W. Sappington, M. Sétamou, and R. J. Coleman. 2004. Influence of different cotton fruit sizes on boll weevil (Coleoptera: Curculionidae) oviposition and survival to adulthood. Environ. Entomol. 33: 443-449.

Grefenstette, B., and O. El-Lissy. 2003. Boll weevil eradication update, pp. 131-141. In Proceedings of the Beltwide Cotton Conferences, 6-10 January, Nashville, TN. National Cotton Council, Memphis, TN.

Hughs, S. E., and M. N. Gillum. 1994. Appendix C -Pink bollworm control in gins, pp. 315-322. In W. S. Anthony and W. D. Mayfield (eds.), Cotton Ginners Handbook. U.S. Department of Agriculture, Agricultural Handbook 503.

Hughs, S. E., and R. T. Staten. 1995. Pink bollworm mortality using large-diameter gin-trash fans. Appl. Eng. Agric. 11: 281-284.

Hunter, W. D. 1904. Controlling the boll weevil in cotton seed and at ginneries. U.S. Department of Agriculture, Farmers' Bull. No. 209.

Hunter, W. D., and B. R. Coad. 1923. The boll-weevil problem. U.S. Dep. Agric., Farmers' Bull. 1329.

Kruskal, W. H. 1952. A nonparametric test for the several sample problem. Ann. Math. Stat. 23: 525-540.

Kruskal, W. H., and W. A. Wallis. 1952. Use of ranks in one-criterion variance analysis. J. Am. Stat. Assoc. 47: 583-621.

Laird, J. W., B. M. Norman, S. Stuller, and P. Bodovsky. 1994. Seed cotton unloading systems, pp. 46-58. In W. S. Anthony and W. D. Mayfield (eds.), Cotton ginners handbook. U.S. Department of Agriculture, Agricultural Handbook 503 .

Lalor, W. F., M. H. Willcutt, and R. G. Curley. 1994. Seed cotton storage and handling, pp. 16-25. In W. S. Anthony and W. D. Mayfield (eds.), Cotton ginners handbook. U.S. Department of Agriculture, Agricultural Handbook 503.

Parnell, C. B. Jr., E. P. Columbus, and W. D. Mayfield. 1994. Abatement of air pollution and disposal of gin waste, pp. 172-194. In W. S. Anthony and W. D. Mayfield (eds.), Cotton ginners handbook. U.S. Department of Agriculture, Agricultural Handbook 503.

Robertson, O. T., V. L. Stedronsky, and D. H. Currie. 1959. Kill of pink bollworms in the cotton gin and the oil mill. U.S. Dep. Agric.-ARS Prod. Res. Rep. No. 26.

Robertson, O. T., D. F. Martin, D. M. Alberson, V. L. Stedronsky, and D. M. McEachern. 1963. Pink bollworm kill with improved gin equipment. U.S. Dep. Agric.-ARS Prod. Res. Rep. No. 73.

Sappington, T. W., A. D. Brashears, M. N. Parajulee, S. C. Carroll, M. D. Arnold, J. W. Norman, Jr., and A. E. Knutson. 2004a. Potential for transport of boll weevils 
(Coleoptera: Curculionidae) to the cotton gin within cotton modules. J. Econ. Entomol. 97: 934-940.

Sappington, T. W., A. D. Brashears, M. N. Parajulee, S. C. Carroll, M. D. Arnold, and R. V. Baker. 2004b. Boll weevil (Coleoptera: Curculionidae) survival through the seed cotton cleaning process in the cotton gin. J. Econ. Entomol. 97: 1323-1329.

Smith, J. W. 1998. Boll weevil eradication: area-wide pest management. Ann. Entomol. Soc. Am. 91: 239-247. van der Laan, P., and L. R. Verdooren. 1987. Classical analysis of variance methods and nonparametric counterparts. Biometrical J. 29: 635-665.

Venette, R. C., R. D. Moon, and W. D. Hutchinson. 2002. Strategies and statistics of sampling for rare individuals. Annu. Rev. Entomol. 47: 143-174.

Received 4 May 2004; accepted 11 July 2004. 